\title{
Effect of Broiler Slaughter Waste Compost on Seed Germination and Growth Performance of Selected Crop Plants
}

\author{
Dissanayake N.U.S.*, Bandara N. J.G.J., Fernando K.M.E.P. \\ University of Sri Jayewardenepura, Sri Lanka \\ *sandalidissanayake89@gmail.com
}

\begin{abstract}
Organic farming is a global trend in green economy. Composting has been promoted as a organic farming method and waste management technique. It has been reported that raw compost made of municipal solid waste (MSW) lacks essential macro and micro nutrients. Slaughter House Waste (SHW) which generally is a cause of concern in waste management is a good source of nutrients. This study was aimed at evaluating growth performance of plants applied with a combination of MSW and SHW. Open windrow method was used to prepare the mixture made of $80 \% \mathrm{MSW}$ and $20 \%$ SHW. In vitro seed germination was tested using the compost suspension and distilled water (as the control). A 1:1 combination of Compost and soil was filled into three pots $(12 \mathrm{~cm}$ diameter) and three green gram seeds were planted in each pot. Another set of three pots was filled with raw compost and in the control, soil was filled into three pots, and three green gram seeds were planted in each pot. The number of germinated seeds was counted and after four weeks the shoot heights, fresh weight and dry weight were measured along with number of leaves of each seedling. A second set of experiments was carried out following the same method with radish seeds. Both green gram and radish seeds showed $100 \%$ germination in compost and distilled water. Remarkable increase in root length was observed in compost compared to distilled water. In the pots $100 \%$ seed germination occurred in both crops in all three treatments. Plants grown in combination of compost and soil showed higher growth performance with more leaves, higher shoot length and higher fresh and dry weights than plants grown in $100 \%$ soil medium. However, poor growth was observed in plants grown in raw compost alone. Results revealed that compost with slaughterhouse waste is an effective organic fertilizer for test crops. The nutrients lacking compost made of just MSW can be improved to a high quality fertilizer by adding SHW. However, compost made of MSW and SHW alone is not suitable for planting crops but this could be used by mixing with soil.
\end{abstract}

Keywords: Compost, Seed germination, Slaughterhouse waste 